Revista de la red interuniversitaria de estudios sobre las literaturas rioplatenses contemporáneas en Francia

$23 \mid 2021$

La vereda de enfrente. Cruces entre las literaturas argentina y chilena del siglo XX

\title{
Comunidad y heterodoxia en el trabajo de Enrique Espinoza en Babel
}

Community and heterodoxy in Enrique Espinoza's work in Babel

Communauté et hétérodoxie dans le travail de Enrique Espinoza dans Babel

Juan José Adriasola y Luis Valenzuela Prado

\section{OpenEdition}

\section{Journals}

Edición electrónica

URL: https://journals.openedition.org/lirico/10989

DOI: $10.4000 /$ lirico.10989

ISSN: 2262-8339

Editor

Réseau interuniversitaire d'étude des littératures contemporaines du Río de la Plata

Referencia electrónica

Juan José Adriasola y Luis Valenzuela Prado, «Comunidad y heterodoxia en el trabajo de Enrique

Espinoza en Babel», Cuadernos LIRICO [En línea], 23 | 2021, Publicado el 15 diciembre 2021, consultado el 07 enero 2022. URL: http://journals.openedition.org/lirico/10989 ; DOI: https://doi.org/10.4000/ lirico.10989

Este documento fue generado automáticamente el 7 enero 2022.

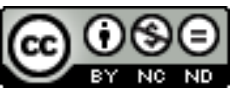

Cuadernos LIRICO está distribuido bajo una Licencia Creative Commons Atribución-NoComercialSinDerivar 4.0 Internacional. 


\section{Comunidad y heterodoxia en el trabajo de Enrique Espinoza en Babel}

Community and heterodoxy in Enrique Espinoza's work in Babel

Communauté et hétérodoxie dans le travail de Enrique Espinoza dans Babel

Juan José Adriasola y Luis Valenzuela Prado
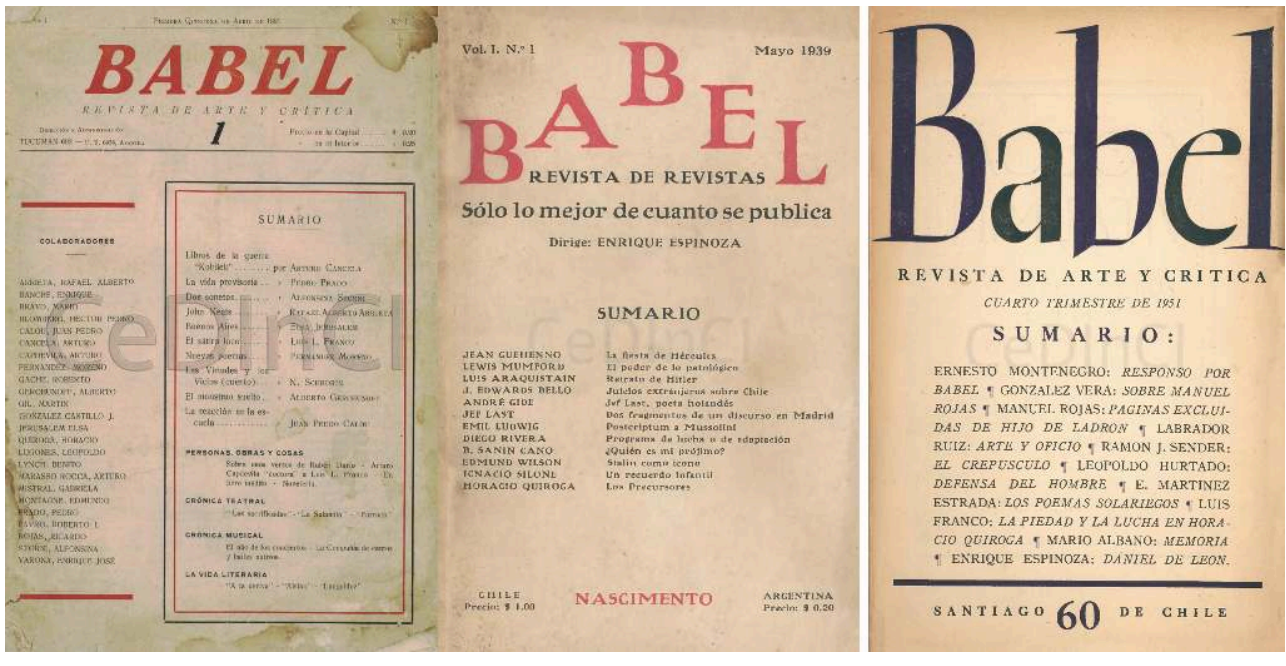

1 La irrupción de revistas en Latinoamérica y en todo el mundo, a comienzos del siglo XX, altera significativamente los modos de producción y circulación intelectual, relevando entre otros, agentes como los editores, traductores y, por cierto, directores de revistas ${ }^{1}$. En este ámbito, Samuel Glusberg (1989-1987), también conocido como Enrique Espinoza, fue una de las principales figuras durante la primera mitad del siglo XX en Argentina y Chile. Editor de libros y revistas, traductor y ensayista, su trabajo lo pone en el centro de la conformación de comunidades intelectuales en el periodo, dentro y más allá de las fronteras nacionales. Llegado a Buenos Aires en 1905, "escapando de las masacres perpetradas contra los judíos en la ciudad rusa donde vivía” (Delgado 2018: 1), 
para luego radicarse en Santiago en 1935 (volviendo a Argentina el año 1973, "días antes del golpe militar en Chile" (Mosqueda 2018: 1), desarrolló en ambos países una profusa actividad editorial, a través de la cual mantuvo relaciones de amistad y colaboración intelectual con algunos de los escritores más importante de la época, entre otros, con Lugones, Martínez Estrada, Quiroga, Mariátegui y Waldo Frank.

Entre los diversos proyectos de los que participa y que él mismo desarrolla -las revistas Cuadernos de Oriente y Occidente, La vida literaria y Trapalanda, entre otras-, no cabe duda de que el proyecto más complejo y de más largo aliento, fue la revista Babel. Esta se publicó en dos épocas, originalmente en Buenos Aires entre 1921 y 1929 y, luego, en Santiago entre 1939 y 1951. En su época chilena, la revista se publicó en dos modalidades: Babel. Revista de revistas (1939-1940), dedicada fundamentalmente a la traducción y republicación de ensayos aparecidos en otros medios; y Babel. Revista de arte y crítica (1941-1951), denominación original de la revista en Argentina, que consideraba tanto traducciones, como ensayos originales de diversos autores, entre ellos del propio Espinoza. El recorrido que se traza a través de la revista, nos permite leer el proceso de su proyecto intelectual y el imaginario comunitario que defiende, por cierto, mediado por el diálogo y la colaboración estrecha con las comunidades formadas en torno a la misma revista. Enmarcada en "el periodo de profesionalización del editor en la Argentina" (Mosqueda 2018: 3), en su primera etapa, Babel se posiciona desde una lectura de su propio soporte, proponiendo la revista como espacio plural, de libre pensamiento y de proyección universal. En torno a ella, se articula una red de intelectuales principalmente argentinos -y, esporádicamente, algunos chilenos-, que retoman y elaboran sobre las premisas del cosmopolitismo modernista. Mediado por el trabajo de Espinoza en revistas como La vida literaria (1928-1932) y su colaboración en revistas chilenas como SECH (1936-1939) ${ }^{2}$, la segunda etapa de Babel retoma estas premisas desde un expreso anticolonialismo, así como un alineamiento político que cruza tanto las páginas de la revista como el núcleo de intelectuales que participan en ella, entre otros, Manuel Rojas, José Santos González Vera, Luis Franco, Ernesto Montenegro y Mauricio Amster ${ }^{3}$.

3 Nuestra intención en este ensayo es estudiar el proyecto de Babel como la puesta en práctica de un deseo comunitario, articulado tanto en la red intelectual que allí se construye como en los modos y mecanismos por los cuales se intenta dar sentido y cohesión a cuerpos heterogéneos de textos y autores. Enfocándonos en el trabajo que desarrolla en ella Espinoza, sus ensayos y dirección editorial, proponemos que la revista funciona como un dispositivo que articula esta comunidad heterodoxa a través de prácticas escriturales y editoriales que afirman el diálogo y el intercambio intelectual, así como sientan las bases de su americanismo cosmopolita y anticolonial. De este modo, como veremos a continuación, la comunidad que se construye opera en la definición simultánea de lo universal y lo local, como categorías que concurren en la experiencia heterodoxa de lo americano.

\title{
Babel. Universalidad y comunidad
}

\author{
"Ahora, pues, descendamos y \\ confundamos allí sus lenguas, para \\ que ninguno entienda" \\ Génesis. La Biblia
}


La historia del pensamiento crítico latinoamericano es heterogénea, en tanto despliega discusiones y debates convergentes en torno a la identidad latinoamericana-identidad común americana o, incluso, comunidad regional-, posterior a los periodos fundacionales del siglo XIX, encuentra diversas aristas en torno a lo propio y lo ajeno; lo nacional y lo cosmopolita; y diversas variantes de lo colectivo y la comunidad. Ángel Rama propone, según expone Hugo Herrera, la posibilidad de leer dos "macromomentos" para estos años de cultura modernizada, uno, desde 1879 hasta los centenarios, llamado "internacionalista"; y el otro, desde los centenarios en adelante, llamado "nacionalista" (Herrera 2020: 32). Estos macromomentos permiten ordenar y leer el programa de Babel y los escritos en los que Espinoza proyecta lecturas de pensadores latinoamericanos que, en su desarrollo internacionalista y nacionalista, piensan el sentido colectivo de la comunidad problematizando la relación entre el rol del intelectual y la relación americana con lo propio y lo ajeno. En esa línea, Espinoza destaca, entre otros, los trabajos de Andrés Bello, José Martí, Pedro Henríquez Ureña y José Carlos Mariátegui, los cuales permiten discutir ciertas matrices universales $\mathrm{y}$ comunitarias del pensamiento crítico latinoamericano de Babel.

Desde Babel, Espinoza entabla un diálogo directo entre el regionalismo, formas propias, e ideas cosmopolitas, ajenas, a las que eran reticente cierto regionalismo nacional ${ }^{4}$. El texto "Colonialismo espiritual" $\left(\mathrm{N}^{\circ} 57,1951\right)$ se abre con un epígrafe de Pedro Henríquez Ureña, que sintetiza el espíritu independentista de la "América española", el cual se replicaría desde Andrés Bello hasta el siglo XX. Para enaltecer ese espíritu colectivo refuta los lineamientos planteados por Américo Castro, quien ilustra su crítica hacia el uso de la lengua española, comparando el francés escrito en Canadá, Haití y Suiza, el cual es "regulado por el francés de Francia" (30), lamentando, de paso, que no suceda lo mismo en el español americano, específicamente de Argentina. Frente a los dichos de Américo Castro, Espinoza sostiene que es "injusto reducir todo aquel movimiento de independencia literaria, exaltado por Martí, Rodó y Rubén Darío, a simple ojeriza o resentimiento" (33), pero, en especial, se vale de Andrés Bello, para quien la "variedad de prácticas es inevitable en estos confines" (34), siendo dificultoso "hacerla desaparecer", provocando "más daño que provecho" (34). Es el mismo Henríquez Ureña, el del epígrafe de Espinoza, quien ve, en Las corrientes literarias en la América Hispánica, a Andrés Bello como el gestor del "deseo de independencia intelectual" (151) en la Alocución a la Poesía; una suerte de "programa editorial". Esta independencia va desde 1800 a 1830, dando paso a otra de "Romanticismo y anarquía", desde 1830 a 1860, caracterizado como un periodo inestable, en el cual la mayor parte de los países "salieron arruinados y con su población diezmada de la larga lucha sangrienta" (167), logrando estabilizarse esta situación entre 1850 y 1870. Sin embargo, según Henríquez Ureña, predomina la organización política en los países independientes, conservando la literatura "todas las funciones públicas que había cobrado con el movimiento de liberación. En medio de la anarquía, los hombres de letras estuvieron del lado de la justicia social, o al menos del lado de la organización política contra las fuerzas del desorden" (171), momento en el que los "hombres de letras fueron (...) por regla general, también hombres de acción" (173). Damos este giro hacia el pasado para sentar las bases del trabajo y horizonte colectivo americano que predomina en las letras desde el siglo XIX hasta el momento en que publica Enrique Espinoza, criticando la posibilidad injusta de "reducir todo aquel movimiento de 
independencia literaria, exaltado por Martí, Rodó y Rubén Darío, a simple ojeriza o resentimiento" (33).

6 En su texto "La torre de Babel" ( $\left.\mathrm{N}^{\circ} 58,1951\right)$, Espinoza refiere a la lectura recurrente, y catastrófica, que se hace del episodio bíblico que da nombre a la revista, esto es, la venganza o el castigo de Jehová. No obstante, Espinoza, partiendo de la base de Goethe y Kafka, proyecta la idea del deseo y de la ambición de llegar alto con la torre. El primero le dice a su amigo Lavater que desea levantar lo más alto posible la cima de una pirámide, sin que su avanzada edad sea un impedimento (48). El segundo, releva la importancia del pensamiento y el deseo en torno a la posibilidad de levantar la torre, el resto es "secundario" (48). Según Espinoza, la heterogénea composición idiomática comienza, en parte, con Sarmiento, quien, en su afán y gusto por las letras francesas e inglesas, inaugura en Chile, con Facundo, su propia Babel. Será Martí, el "apóstol cubano" que vapulea a los pensadores que "recalientan las razas de librería" (49), quien introduce en una correspondencia periodística un giro en ese pensamiento: "Por el cielo están entrando los hombres: Babel es toda la tierra; sólo que ya no se confunden las lenguas" (49), apuntando a una idea universal y conjunta, pero en su diferencia. Si Martí escribe esto en el norte, Rubén Darío hará lo propio en el sur, desde su torre de marfil: "Los mismos ruiseñores cantan los mismos trinos / y en diferentes lenguas es la misma canción" (49), sosteniendo, con mayor énfasis la analogía que anticipaba Martí: "Aquí se confunde el tropel / de los que a lo infinito tienden / y se edifica la Babel / en donde todos se comprenden" (49). De la torre de marfil pasa a la de Babel. Espinoza culmina con una pregunta cuya intención es tajante: “ ¿Cabe, tras tanto testimonio irrecusable, alguna duda de que el verdadero lugar del escritor en nuestra época es la torre de Babel y no la torre de marfil?" (49). El lugar del escritor es Babel, el epítome de la universalidad y la comunidad.

7 Desde 1880, José Martí es de los primeros latinoamericanos en "reflexionar sobre el relativo desprendimiento de la literatura de la vida pública, desplazamiento que para él cristalizaba uno de los rasgos distintivos de la 'crisis' moderna" (Ramos 1989: 158), acorde con el "proyecto martiano de una modernidad contrahegemónica" (Ramos 2018: 35). Martí volvió de forma constante a la idea de una América, "nuestra América mestiza" ("Nuestra América" 35), en cuya formación asumirá "inevitablemente el sello de la civilización conquistadora; pero mejorará, adelantará y asombrará con la energía y creador empuje de un pueblo en esencia distinto, superior en nobles ambiciones, y si herido, no muerto" ("Los códigos nuevos" 8). Se trata, así, de un proceso y operación constante de nuestra región de "barrer ruinas" y echar sobre estas "cimientos de una nacionalidad viva y gloriosa" ("Los códigos nuevos" 13). Leemos, sin duda, un modo entusiasta de pensar el territorio americano, con una actitud colectiva, levantada y asumida por el mismo Martí, "para servirla y honrarla (...) con la determinación y la capacidad de contribuir a que se le estime por sus méritos, y se la respete por sus sacrificios" ("Discurso..." 30), es decir, ni como siervos ni como aldeanos pasivos. El sujeto de esta América, enfatiza Martí, no será el "aldeano vanidoso" que cree que "el mundo entero es su aldea" ("Nuestra América" 31), ni la "masa inculta" ("Nuestra América" 33). Martí apuesta por una América sin razas, diversa en "forma y en color" ("Nuestra América" 39).

8 Un eje que tiende un puente con la lectura de la heterodoxia y el universalismo de Babel, es el del horizonte clásico de Grecia. Por un lado, Henríquez Ureña hace referencia a Grecia como la "madre de tantas invenciones estupendas" (en Maíz 2018: 
107), a diferencia de la Grecia referida por Martí: "La historia de América, de los incas, acá ha de enseñarse al dedillo, aunque no se enseñe la de los arcontes de Grecia. Nuestra Grecia es preferible a la Grecia que no es nuestra" ("Nuestra América" 34). Esta discusión es esbozada por Espinoza, en 1944, en su lectura del libro El pensamiento de Rodó de Emilio Oribe. Sin adentrarnos en el libro comentado ni en el contenido del texto de Espinoza, resulta relevante reflexionar la idea de comunidad americana del director de Babel. Este menciona el dardo enviado por Mariátigui a Rodó, en 1929, poniendo énfasis que se trata de un momento previo "a la política del buen vecino, y de toda la oficialización panamericana de la inteligencia" (Espinoza 1944b: 159). Mariátegui afirma lo ridículo de hablar del contraste de una "América sajona materialista y una América latina idealista, entre la Roma rubia y la Grecia pálida" (159), tratándose de tópicos "desacreditados" que redundan en que el "mito de Rodó" no va más. Los matices en torno a la filiación griega refuerzan las querellas en torno a las formas de pensar lo propio, lo comunitario, lo americano.

9 La tensión que provoca José Carlos Mariátegui lo lleva a constituirse, según Espinoza, en la figura de la que "nuestro idioma" carecía, en tanto "verdadero teórico revolucionario capaz de vivir su pensamiento a la manera heroica de Marx y Engels" (1950: 121), quizás el "único líder revolucionario, en pensamiento y acción, después de Recabarren, el pionero" (121), un "hombre y un escritor sin dobleces" (122). En Mariátegui, específicamente en sus Siete ensayos de interpretación de la realidad peruana, aparecido en 1928, se elaboran lineamientos en torno a diversos aspectos que desembocan en una lectura y propuesta de lo que podríamos denominar como comunidad, la cual conlleva diversas formas de interacción y hacer político, siendo entendida como vínculo patrimonial y de trabajo, cooperativo y solidario, "expresión empírica de un espíritu comunista" (Mariátegui 2014: 79). Espinoza destaca que para Mariátegui la literatura no iba separada de la historia ni de la política, por el contrario, estas se articulaban como una "representación perdurable" (1950: 122), determinantes para la praxis y "el sentido social de la vida humana" (122). Tras la muerte de Mariátegui, Espinoza sostiene que "no ha surgido otro líder de su estatura en América" (124).

\section{Heterodoxia y reescritura}

10 En el retrato que le dedica a Espinoza, en Algunos, González Vera comenta sucintamente el rasgo medular de su principal proyecto editorial. "Babel -nos dice-, mas no con el sentido de mera confusión, sino de afinidad” (1967: 44), recordando luego la cita al "Canto a la Argentina" de Darío ya evocada aquí, mantra tanto de la revista como de su director ${ }^{5}$. Un lugar de enunciación y un modo de producción, que, a su vez, busca constituir un modo de circulación particular, un mundo de lectores, que González Vera caracteriza como "heterodoxos" (52). Babel, en tanto comunidad heterodoxa, afín en la diferencia: este es el orden de sentido que enmarca, orienta y, en definitiva, traza las señas de identidad del proyecto.

11 Afinidad en la heterodoxia. Se la descubre en la diversidad de perspectivas que busca acoger la revista -desde su inicio en 1921 y con especial intensidad en la segunda época-, que Espinoza defiende, entre otras, bajo las nociones de libertad de pensamiento, cooperación intelectual y, muy significativamente, americanismo. Así lo plantea al inaugurar, con "Resurrección y símbolo" ( $\left.{ }^{\circ} 1,1939\right)$, la época chilena de 
Babel: "Libres de prejuicios, como buenos americanos, haremos naturalmente lugar a la polémica esclarecedora, seguros de que para tener razón no es preciso de ningún modo cortar la cabeza del adversario" (1). La actividad intelectual opera para Espinoza en el diálogo, incluso, y quizás especialmente, cuando este es antagónico. Esta concepción la vemos desplegada en sus propios ensayos, tanto en los que celebra la obra y figura de otros intelectuales, como en los que asume una labor antagónica. Ejemplo temprano de esto último es “'Babel' versus 'Crítica'. David contra Goliat” $\left(\mathrm{N}^{\circ} 22,1927\right)^{6}$. Más allá de las situaciones que desmiente Espinoza, la crítica y su indignación se dirigen a lo que presenta como un intento de suprimir la diversidad de voces. Actividad editorial mezquina, que no admite el retruco de un intelectual criticado, y que alimenta y redunda en un escenario donde "la libertad de pensamiento es un mito" (s/p). Se funden en esta crítica los descargos personales del editor, con una suerte de proclama que particulariza el proyecto Babel en su oposición con Crítica: no se trata ya solamente de aquella injuria personal, sino de la escena y el modo de producción intelectual que la revista de Espinoza, en su etapa argentina, se propone desafiar y renovar.

12 A la inversa, el recurso más frecuente en los comentarios celebratorios que realiza tanto a intelectuales como a revistas, se funda en la afirmación de formas de lo dialógico y lo diverso. Constelación de conceptos que atraviesa ambas épocas de Babel, la clave fundamental de un americanismo que entrama la experiencia y práctica de lo universal con el ejercicio de una intelectualidad libre, que, en la etapa chilena de la revista, acabará vinculándose directamente a una forma de pensamiento anticolonial. Esto puede observarse, como discute Antonia Viu a propósito del tratamiento de la guerra en Babel. Revista de revistas, en recursos como la selección y el montaje de artículos, las traducciones, recortes y comentarios, a través de los cuales se articula "una comunidad afectiva particular, una comunidad vinculada al americanismo y a la Cooperación Intelectual como movimiento internacional" (2018: 420). La construcción de esta comunidad americanista a la vez que internacional implica, por cierto, configurar un contrapunto local que sostenga aquel diálogo. En otras palabras, la tarea que asume la revista, no solo busca involucrar a América en las discusiones globales, sino también movilizar una serie de definiciones que particularizan lo americano contemplando en su seno la idea de la universalidad.

Esta particularización puede observarse en la genealogía literaria americana, que Viu observa un poco más adelante (2018: 426), retomando la reflexión de Espinoza en "Del idioma y de la raza. Testimonios anticoloniales" $\left(\mathrm{N}^{\circ} 52,1949\right)$. En este ensayo, el autor realiza dos movimientos significativos. El primero, relativo a la construcción de aquel canon regional, al que busca darle la consistencia histórica de una "resistencia secular ininterrumpida" al dominio colonial español -persistente en el plano de la cultura-, "desde Sarmiento hasta Lugones, pasando por Martí, Darío, Sanin Cano y demás escritores anticoloniales" (Espinoza 1949: 248). Entre los referentes que enumera aquí Espinoza destaca notoriamente la opción por aquel momento internacionalista, es decir, ese que cifra lo americano en un balance dialógico entre lo propio y lo ajeno. El frecuente uso de la palabra "universal", como valor propio de un modo de producción intelectual americano, es una de las muchas marcas a través de las cuales se afirma esta posición. Así vemos, por ejemplo, cómo tempranamente, para destacar la figura de Alfonso Reyes, lo caracteriza como "un espíritu universal abierto a todas las corrientes civilizadoras" (1927b: s/p); y luego, más de una década después, persiste la noción en su 
retrato de Guillermo Enrique Hudson, a quien estima "intérprete universal de su tierra incógnita" (1941a: 68).

La celebración de lo universal y de lo heterodoxo nos lleva al segundo movimiento en "Del idioma y la raza...": la forma particular en que se despliega la noción de anticolonialismo. Dice Espinoza: "ni Sarmiento ni Lugones fueron antiespañoles en sentido estricto, sino más bien anticoloniales. Enemigos del colonialismo" (1949: 243). El asunto, vemos, trasciende un esquema de oposición nacional, distinguiéndose de la resistencia al ejercicio del dominio colonial, a la experiencia y la estructura de un intercambio desigual. Esta distinción es consistente con el antagonismo que sostiene Espinoza en Babel con los nacionalismos de la primera mitad del siglo $\mathrm{XX}^{7}$. Espinoza parece observar en la afirmación nacional, como lo planteaba Alain Badiu hace algunos años, "el lastre de una identidad cerrada -y siempre ficticia" que redunda en la presencia de un "Estado despótico, que hace existir violentamente la ficción que lo funda" (2014: 17). En cambio, en el espíritu de estos testimonios literarios anticoloniales, observa la potencia de un pueblo que se afirma "en la perspectiva de su existencia histórica", trascendiendo la negación implícita en la dominación colonial e instituyéndose "en función del futuro anterior de un Estado existente" (2014: 17) y, podríamos agregar, del sistema mismo de oposiciones que instaura la ficción de la identidad cerrada que resguarda aquel Estado nacional.

Este movimiento, la afirmación de un americanismo anticolonial que sostiene una oposición activa con el ideario nacionalista, nos ayuda a precisar el sentido de lo universal que defiende Espinoza. Aquella Torre de Babel que identifica como "el verdadero lugar del escritor en nuestra época" (Espinoza 1951b: 49), resuena con fuerza en la idea del "internacionalismo connatural" del espíritu americano que Alfonso Reyes desarrolla entre los 30 y los 40, y que María Teresa Gramuglio llama a reconsiderar en su estudio sobre los cosmopolitismos de las literaturas periféricas (2012: 373). En una nota agregada con posterioridad a su conferencia "Notas sobre la inteligencia americana" (1936), Reyes glosa el término -introducido en función de una "inclinación pacifista" propia de la inteligencia americana (1997: 87)- poniéndolo en relación con el de una "síntesis de cultura", que llegaría a constituir "un nuevo punto de partida, una estructura entre los elementos anteriores y dispersos, que -como toda estructura- es trascendente y contiene en sí novedades" (1997: 87-88). En "Posición de América" (1942), Reyes vuelve sobre esta reflexión, relacionándola de forma explícita con la experiencia colonial, que opera como el sustrato histórico del que se desprende la necesidad y la "educación de universalismo (...), inesperado efecto benéfico de la formación colonial. El ciudadano de las grandes naciones creadoras de cultura casi no tiene necesidad de salir de sus fronteras lingüísticas para completar su imagen del mundo. El ciudadano de la antigua colonia tiene que ir a la vida internacional para completar tal imagen y, además, está acostumbrado a buscar en el exterior las fuentes del saber" (1997: 264).

La universalidad aparece como hecho ineludible, propiamente americano. En el sentido del ingreso, por fuerza, del continente en el esquema global de organización geopolítica y circulación económica que, a través de la empresa colonial, llegará a consolidar las formas modernas del capitalismo ${ }^{8}$. Junto con eso, lo es también por el sentido urgente de carencia que la estructura colonial impone sobre las comunidades colonizadas, la experiencia de un saber y una existencia cultural desplazada. La misma estructura colonial que, según Achille Mbembe, satura la representación de lo universal a través 
de la normalización del centro (su lógica, su discurso, su cultura) como estructura base y condición genérica ${ }^{9}$, propicia para Reyes la proyección connatural de la América colonizada hacia una experiencia de universalidad que le sería particular y que llegaría a trascender el dictado del propio orden colonial. La precisión sobre su idea de síntesis tensa justamente esta relación: no se trata de "un compendio" de aquel universal-ajeno, sino de "un punto de partida", que activa la posición irreductible del otro-colonizado, ya no en el encierro y la repetición, sino en la agencia creativa de su actividad en la experiencia universal.

17 Esta premisa, en el proyecto de Espinoza, se despliega en movimientos concurrentes de apertura internacional y particularización local. ${ }^{10} \mathrm{En}$ Babel, la revista y lugar que busca simbolizar, lo universal opera como "el lugar de una multiplicidad de singularidades cada una de las cuales no es más que lo que es, es decir, lo que las une y las separa de otras singularidades" (Mbembe 2016: 248). Esto se traduce en la revista en una serie de prácticas que buscan integrar América en los intercambios de una comunidad global de por sí heterogénea, a la vez que resaltan su singularidad a través de la afirmación de su propia actividad intelectual. Si observamos la interacción entre las colaboraciones locales y europeas en la revista, especialmente en su época chilena, podemos identificar un ejercicio consistente con la idea de la reescritura o reescenificación poscolonial, como la ha descrito Ankhi Mukherjee: series de intervenciones indicativas de una recepción y ocupación del canon occidental, que performan un movimiento, desde el consumo y la repetición y la negación pasivas, hacia actos críticos y literarios de carácter autónomo (2014: 23). Es decir, interrupciones al patrón de circulación y al orden jerárquico propios del intercambio colonial. En la práctica literaria, intervenciones que alteran e interrumpen la unicidad del original, su carácter homogéneo en tanto original, ingresándolo, de esa forma, en un orden de sentido y una implicación política diferentes (Mukherjee 2014: 215-216).

En el trabajo de Espinoza en Babel, estas intervenciones operan en un lugar intermedio entre la actividad editorial y la creativa. Viu, en Materialidades de lo impreso, comenta dos procedimientos que podríamos enmarcar dentro de lo que entendemos aquí como recursos de reescenificación: la intervención creativa en la selección de fragmentos y opciones de traducción de los artículos publicados (2019: 144-145), y el ejercicio de montaje editorial de los ensayos en cada número (146-147). Ambos recursos son indicativos, para Viu, de la intensa actividad creativa que mantiene la revista aun durante los años que se aboca a la traducción y republicación de artículos aparecidos en otros medios. El ejercicio de "digestión" que Viu observa en ellos, sirve al propósito de involucrar a Latinoamérica en las discusiones sobre la guerra y la cooperación intelectual, que se desarrollan en el periodo (147). A la vez, la práctica misma de las intervenciones que destaca -entre otras, la deslocalización del conflicto (144) y la asociación poética y por contagio entre mutilación y necesidad de cooperación (147)constituye a Latinoamérica como agente relevante en estas discusiones. El ejercicio de reescritura y reescenificación, podríamos agregar, se ve también en el tránsito que implican estas operaciones, de una lógica de reproducción-difusión -de las noticias y reflexiones sobre la guerra europea- a una de producción-creación -del lugar y la actividad americana en el escenario global.

19 Estos recursos se mantienen en la siguiente y última fase de Babel. Revista de arte y crítica. Junto con ellos, Espinoza introduce otro que podríamos identificar como una práctica de encuadre o puesta en situación. Nos referimos a la serie de ensayos que 
publica sobre autores. Una suerte de prólogos no declarados que desbordan el género, ya que no solo anticipan e introducen una obra y su apreciación, sino que llegan a establecer un marco de sentido y valoración propio de la revista, de los múltiples diálogos que esta busca. Es el caso, entre otros, de "Centenario de una amistad ejemplar", seguido de una selección de "Correspondencia inédita" de Marx y Engels ( $\mathrm{N}^{\circ}$ 23, 1944); "Ignazio Silone y el amor a la verdad", seguido de "¡Solo la verdad nos salvará!" del autor ( $\left.\mathrm{N}^{\circ} 27,1945\right)$; "La tragedia de Walther Rathenau", seguido de sus "Palabras proféticas" ( $\left.\mathrm{N}^{\circ} 39,1947\right)$; y “André Gide, uno y diverso", seguido de "Páginas recobradas" del autor ( $\left.\mathrm{N}^{\circ} 43,1948\right)$. Nuevamente, enfrentamos una práctica en la que confluye la actividad creativa con la editorial. Su efecto no está contenido propiamente en los escritos de Espinoza, sino que se completa en la interacción dialógica que establecen con los textos que los siguen. La operación escritural, en su relación con la editorial, funciona así como puesta en situación, en el sentido de que interviene los textos precedidos, poniendo de relieve aspectos particulares de sus autores y sus condiciones de producción; intervención que modela, de este mismo modo, las condiciones de su recepción. En el caso de Marx y Engels, por ejemplo, la consideración de Espinoza enmarca la producción de las cartas en la experiencia de la camaradería, significativamente abordada desde las claves del diálogo, la colaboración intelectual y el compañerismo en la resistencia. Estas virtudes que destaca Espinoza, su ejemplar amistad, se entraman con dos definiciones fundamentales: por un lado, la defensa del espíritu revolucionario y, por extensión, la negación del "socialismo de los necios"; y, por otro, la fundación del socialismo "de los trabajadores internacionales sin vallas de ninguna clase" (1944a: 68). En el ensayo la definición es una sola: la comunidad internacional conforma la vía de la verdadera revolución, tanto como el compañerismo en el diálogo intelectual y en la resistencia constituye el espíritu revolucionario. El contenido de las cartas que se reproducen a continuación resulta, entonces, ya inmerso en un diálogo y en un mundo de sentido que las orienta, no solo en función de los marcadores que destaca Espinoza, sino también en relación con su lugar dentro de los diálogos e intercambios intelectuales propios de la revista. En otras palabras, al mismo tiempo que se las interviene, acercando la interacción entre Marx y Engels al lector americano, en la dimensión internacional de su espíritu revolucionario, se avanza desde la lógica americana de la revista hacia ellos, a través del cruce productivo entre revolución y colaboración dialógica. Algo similar podemos observar, ya desde el título, en el caso de "André Gide, uno y diverso": el autor francés entra enmarcado en el código fundamental de Babel, la afirmación de una singularidad abierta y necesariamente inmersa en prácticas heterodoxas. En el escrito de Espinoza, es más, el lugar de Gide de forma casi inmediata se americaniza. Sus palabras sobre la afirmación de lo propio, resistiendo la influencia, adquieren rápidamente en el texto la impronta del anticolonialismo babélico. Escribe sobre ellas Espinoza:

¡Cuán a menudo estas palabras de Gide fueron parafraseadas entre nosotros! Pero no en su sentido amplio, generoso, humano. De modo extraño, al paso de un continente a otro, su alcance disminuía en vez de aumentar. El problema de lo auténtico e irreemplazable, tornábase acá: colonialismo espiritual, en el peor de los casos; y en el mejor: provincianismo indígena o criollo. (1948a: 3)

La crítica nos ubica, como podemos ver, ante el binario colonial (reproducción/ negación en tanto absolutos) que Babel se propone superar. Su elaboración, en el diálogo que se introduce y se desarrolla con las páginas que siguen de Gide, adquiere también un valor performativo. Afirma la necesidad del intercambio heterogéneo, al 
mismo tiempo que lo practica: en el propio diálogo y, también, en la puesta en situación que se apropia de la escritura de Gide y la involucra en la discusión sobre la colonialidad. En el contexto de este diálogo, las palabras con las que abren esas "Páginas recobradas" adquieren a su vez un valor inmediatamente americano. Dice: "De todos los «grandes autores» (no puedo emplear esta expresión sin sonreír) los que me han enseñado menos son, sin duda, los franceses. Y no podría ser de otra manera. Los tengo en la sangre, en el cerebro; desde antes de leerlos estaba hecho de ellos" (Gide 1948: 13). Más allá de lo que pueda seguir, y del contexto original en el que Gide pueda haber planteado la reflexión, aquí, en este intercambio, el sentido nos remite directamente a las consideraciones sobre la heterodoxia que cruzan la revista y, aun paradójicamente, a su valor anticolonial. El texto, e incluso la figura del autor, funcionan, de esta forma, inmersos ya en el esquema y la comunidad de Babel.

\section{A modo de conclusión}

Cuando Enrique Espinoza comenta y celebra, en el número de septiembre-octubre de 1944, el cuarto de siglo de la revista Repertorio Americano, aplaude la "profusa labor", con errores menores, la cual, "vista en conjunto adquiere un valor innegable como testimonio de toda una época" (107). Espinoza entiende el funcionamiento y el impacto de una revista en el campo intelectual, comfigurado por otras revistas y también por la propia, desde la cual comenta y desde la cual se reconoce involucrado en las prácticas colectivas que impulsan y conectan estos proyectos editoriales. Babel es protagónica en este contexto, desde su primera década argentina hasta sus últimos números en Chile, a través de páginas y lazos intelecutales formados en el transcurso de los años; conectando tanto los territorios como los momentos que marcaron ambas épocas de la revista. Un hecho colectivo, destacábamos más arriba; ciertas ideas que lo organizan y cierto modo específico de hacerlas parte de una vida pública, de circularlas. En este caso, la idea de lo americano desde una experiencia fundamentalmente heterodoxa y dialógica, por un lado; por otro, la propia comunidad que construye y a través de la cual Espinoza vive colectivamente, tanto por medio de los intelectuales que congrega en sus números, como en el ejercicio sostenido de diálogos y propuestas que redefinen tanto sus horizontes como sus modos de interacción.

La comunidad levantada por Babel es, sin dudas, americana, pero es, al mismo tiempo, una comunidad global y compleja, en donde el corazón del espíritu anticolonial que la define, no se configura desde la tajante negación ni reproducción ajena, sino en el cruce, la mixtura, la intervención activa y dialogante, en rigor, en la participación activa y crítica latente en las dos vidas de Babel.

\section{BIBLIOGRAFÍA}

Badiou, Alain, "Veinticuatro notas sobre los usos de la palabra "pueblo»”, Badiou, Alain et al, ¿Qué es un pueblo?, Cecilia González y Fermín Rodríguez, trad., Santiago, LOM, 2014, 9-18. 
Delgado, Verónica, “Semblanza de Samuel Glusberg (1898-1987)". Biblioteca Virtual Miguel de Cervantes - Portal Editores y Editoriales Iberoamericanos (siglos XIXXXI) - EDI-RED, 2018: http:// www.cervantesvirtual.com/obra/samuel-glusberg-kischinev-1898--buenos-aires1987semblanza-888975/

Espinoza, Enrique, “André Gide, uno y diverso" Babel. Revista de arte y crítica n 43, 1948a, p. 3-12.

---, “'Babel' versus ‘Crítica', David contra Goliat” [firmado Samuel Glusberg] Babel. Revista de arte y crítica $\mathrm{n}^{\circ} 22,1927 \mathrm{a}, \mathrm{s} / \mathrm{p}$.

---, “Centenario de una amistad ejemplar", Babel. Revista de arte y crítica n² 23, 1944a, p. 65-68.

---, “Colonialismo espiritual”. Babel. Revista de arte y crítica n 57, 1951a, p. 29-34.

---, “Del idioma y la raza. Testimonios anticoloniales”, Babel. Revista de arte y crítica n 52, 1949, p. 239-248.

---, "El fantasma mete ahora miedo en América”, Babel. Revista de arte y crítica n 44, 1948b, p. 98-102.

---, “El pensamiento de Rodó”, Babel. Revista de arte y crítica n² 24, 1944b, p. 159-160.

---, “José Carlos Mariátegui, Amauta o guía de una generación", Babel. Revista de arte y crítica n 54, 1950, p. 120-124.

---, “La reconquista de Hudson", Babel. Revista de arte y crítica n 18, 1941a, p. 67-88.

---, "La torre de Babel”, Babel. Revista de arte y crítica n 58, 1951b, p. 47-50.

---, “La tragedia de Walther Rathenau”, Babel. Revista de arte y crítica n 39, 1947, p. 128-141.

---, "Los escritores frente a León Trotsky”, Babel. Revista de arte y crítica, n 15-16, 1941b, p. 131-145.

---, “Notas y comentarios por la Redacción. Alfonso Reyes”, Babel. Revista de arte y crítica n²4, $1927 \mathrm{~b}, \mathrm{~s} / \mathrm{p}$.

---, “Nuestros artistas. Juan Hohmann”, Babel. Revista de arte y crítica n² 24, 1927c, s/p.

---, “Resurrección y símbolo”, Babel. Revista de revistas n 1, 1939, p. 1-2.

Gide, André, “Páginas recobradas", Babel. Revista de arte y crítica nº 43, 1948, p. 13-20.

Gramuglio, María Teresa, Nacionalismo y cosmopolitismo en la literatura argentina, Rosario, E. Municipal de Rosario, 2012.

González Vera, José Santos, Algunos, Santiago, Nascimento, 1967.

Henríquez Ureña, Pedro, "El descontento y la promesa”. Crítica literaria y teoría cultural en América Latina. Para una antología del siglo XX. Clara María Parra Triana y Raúl Rodríguez Freire. Valparaíso: Ediciones Universitarias de Valparaíso, 2018.

---, Las corrientes literarias en la América Hispánica. México DF: Fondo de cultura económica, 2014.

Hernández, Sebastián. "Entre Babel y Babel. Proyectos editoriales y culturales de Enrique Espinoza en Argentina y Chile (1928-1939)" Meridional. Revista Chilena de Estudios Latinoamericanos n¹3, oct. 2019-mar. 2020, p. 65-90

Herrera Pardo, Hugo, "Prólogo a la nueva edición", Las máscaras democráticas del modernismo, Ángel Rama, Mímesis, Valparaíso, 2020.

Jitrik, Noé, Las contradicciones del modernismo, México DF, Colegio de México, 1978. 
Maíz, Claudio, "Pedro Henríquez Ureña", Crítica literaria y teoría cultural en América Latina. Para una antología del siglo XX, Clara María Parra Triana y Raúl Rodríguez Freire, Valparaíso, Ediciones Universitarias de Valparaíso, 2018.

Mariátegui, José Carlos, Siete ensayos de interpretación de la Realidad peruana, Lima, Ediciones RDC, 2014.

Martí, José. "Nuestra América", "Discurso pronunciado ante la Sociedad", "Los códigos nuevos". Nuestra América. Caracas, Ayacucho, 2005.

Mbembe, Achille, Crítica de la razón negra, Enrique Schmukler, trad. Buenos Aires, Futuro anterior, 2016.

---, On the poscolony, Berkeley / Los Angeles / Londres, U. California Press, 2001.

Mukherjee, Ankhi, What is a classic? Postcolonial rewriting and invention of the canon, Stanford, Stanford U. Press, 2014.

Mosqueda, Ana, "Semblanza de Biblioteca Argentina de Buenas Ediciones Literarias (B. A. B. E. L.) (1922-1981)". En Biblioteca Virtual Miguel de Cervantes - Portal Editores y Editoriales Iberoamericanos (siglos XIX-XXI) - EDI-RED, 2018: http://www.cervantesvirtual.com/obra/ biblioteca-argentina-de-buenas-ediciones-babel-1922-1981-semblanza877789/

Ramos, Julio, “Tópicos de la fundación: Poesía y nacionalidad en José Martí”, Desencuentros de la modernidad en América Latina. Literatura y política en el siglo XIX, México D.F, FCE, 1989.

---, "José Martí", Crítica literaria y teoría cultural en América Latina. Para una antología del siglo XX, Clara María Parra Triana y Raúl Rodríguez Freire, Valparaíso, Ediciones Universitarias de Valparaíso, 2018.

Reyes, Alfonso, Obras completas XI. Última Tule, Tentativas y orientaciones. No hay tal lugar, México DF, F.C.E., 1997.

Rodó, José Enrique, "Fragmentos de crítica”, Crítica literaria y teoría cultural en América Latina. Para una antología del siglo XX, Clara María Parra Triana y Raúl Rodríguez Freire, Valparaíso, Ediciones Universitarias de Valparaíso, 2018.

Tejeda, Guillermo. Amster. Santiago: Ediciones Universidad Diego Portales, 2011.

Viu, Antonia, "Lloremos y traduzcamos. La segunda guerra mundial y la cooperación intelectual desde Babel. Revista de Revistas (1939-1940)" en Rafael Gaune y Claudio Rolle, eds., Homo dolens. Cartografías del dolor: sentidos, experiencias, registros, Santiago, FCE, 2018, pp. 418-434.

---, Materialidades de lo impreso. Revistas latinoamericanas 1910-1950, Santiago, Metales Pesados, 2019.

\section{NOTAS}

1. Quisiéramos agradecer el notable trabajo que realiza el Centro de Documentación y de Investigación de la Cultura de Izquierdas (CeDInCI), quienes generosamente han puesto a disposición, a través del sitio web América Lee, entre otras revistas, la totalidad de los números de Babel en formato digitalizado.

2. En "Entre Babel y Babel. Proyectos editoriales y culturales de Enrique Espinoza en Argentina y Chile (1928-1939)" Sebastián Hernánez elabora sobre este período en el trabajo de Espinoza, haciendo énfasis en el desarrollo conceptual de su posicionamiento político, así como en el desarrollo de sus redes de colaboración en Chile. 
3. En su libro Amster, Juan Guillermo Tejeda cuenta que Espinoza consideraba a Babel "una de sus obras personales, una prolongación natural de su organismo, por mucho que la revista se hiciese gracias a un esfuerzo más o menos colectivo", un "club virtual o semestral", desde el cual, en su etapa chilena, Mauricio Amster, Enrique Espinoza, José Santos González Vera, Ernesto Montenegro y Manuel Rojas conviven con colabordadores lejanos geográficamente, como Thomas Mann, Hannnah Arendt, André Gidé, Albert Camus, León Trotosky y Gabriela Mistral, lo que replica el gesto inicial, en 1921, de atraer "en torno a sí a personalidades relevantes, entre ellas Horacio Quiroga, Leopoldo Lugones, Mariano Picón Salas, Arturo Uslar Prietri, Augusto D’Halmar, Pedro Prado y Juan Carlos Mariátegui" (2011: 98). En ese sentido, lo local y lo cosmopolita se da tanto como forma vinculante y comunitaria, como reflexiva en lo referido a esos ejes.

4. Estas posiciones aparecen en la revista (en su última etapa en particular) referidas y criticadas como autoctonismos. El ejemplo más prominente a este respecto es el artículo de Mariano Picón Salas, "Americanismo y autoctonismo", en Babel n 3, 1939: 78-81. Aparece también como comentario recurrente en el ensayo de Ciro Alegría, "Impresión de José Carlos Mariátegui", quien lo celebra como "gran americano" y se detiene a distinguir "americano" de "un pintoresco autoctonismo" ( $\left.N^{\circ} 13,1940: 52-53\right)$.

5. Espinoza cierra con la cita su "Resurrección y símbolo", texto inaugural de la segunda época, chilena, de la revista (1939: 2). Vuelve sobre ella en el comentario al "Mester de Judería, de Carlos Grünberg" (1945: 95); sin citarlo, alude brevemente al poema de Darío y su significación para la revista en "Babel cumple diez años en Chile" (1949: 69); y, una vez más, recupera la cita en “Torre de Babel” (1958: 45).

6. En esta publicación se reproduce parcialmente un intercambio de cartas publicadas en Carátula. En ellas Espinoza acusa una representación malintencionada de su persona y su trabajo por parte del editor en la revista Crítica. La situación es agravada por el hecho de que el director de Crítica hace caso omiso de la respuesta y aclaración que envía Espinoza, razón por la cual decide publicarla en Carátula, donde se desarrolla la polémica resumida en este artículo de Babel.

7. A modo de ejemplos: al comentar la figura de Juan Hohmann, y la circulación de ideas nuevas, comenta al paso la realidad de una "Europa que ha zozobrado en el pantano sangriento de la guerra y en la anticultura nacionalista" (1927c: s/p); en su tributo a Trotsky, en referencia a socialistas europeos (noruegos, franceses y españoles) que cierran filas con Stalin, plantea "estos poltrones socialdemócratas soñaban vencer al fascismo internacional con discursos nacionalistas (...) haciendo finalmente causa común con la burocracia rusa, no contra sus verdaderos enemigos capitalistas" (1941b: 135); en su comentario, a cien años del Manifiesto de Marx y Engels, en el que describe el "petimetre nacionalista, hijo o abogado del patrón" como "enemigo acérrimo de la clase trabajadora organizada en general" (1948b: 98); y, por último, a propósito de Walther Rathenau, discurre sobre "la salud moral de Alemania, herida de muerte por el nacionalismo, harto agresivo en su impotencia esencial" (1947: 133).

8. Ver, entre otros, el ensayo de Anibal Quijano e Immanuel Wallerstein, "La americanidad como concepto, o América en el moderno sistema mundial"; y también el conocido ensayo de Quijano, "Colonialidad del poder, eurocentrismo y América Latina".

9. Plantea Mbembe en On the poscolony: "colonial discourse ends up producing a closed, solitary totality that it elevates to the rank of a generality. And so reality becomes enclosed within a pre-ordained madness. How could it be otherwise, since the actual is 
no longer perceived except through the mirror of a perversity that is, in truth, that of the subject uttering this discourse? Colonial language thus advances, deaf to its silent vibrations and endlessly repeating itself. In its grip, the Other is never him/herself, but is always the echo of our irreducibility" (2001: 178).

10. La etapa argentina de Espinoza cuenta con una incipiente colaboración y vínculo con escritores chilenos. En los $\mathrm{n}^{\circ} 1$ y 4 , abril y mayo de 1921, Pedro Prado escribe "La vida provisoria" y "El arte de vagar". En los $\mathrm{n}^{\circ} 4,7$ y 12, aparece Gabriela Mistral, primero, en el texto de Vicente Medina, "Gabriela Mistral", en abril de 1921, luego con el poema "Balada", en septiembre 1921, y "El ensueño", en febrero febrero de 1922. En el n 19, mayo 1926, Mistral publica el texto "Lugones", y en el 23, abril 1927, el texto "A Rafael Alberto Arrieta". En el n 16, 15 de abril 1925, Armando Donoso publica "Un libro de Nicolás Coronado" y también aparece "Una carta de Eduardo Barrios", a Samuel Glusberg. En el n²1, agosto 1926, Ernesto Montenegro, quien tendrá un rol importante en la etapa chilena posterior, publica "Horacio Quiroga, pariente literario de Rudyard Kipling y Jack London". En el $\mathrm{n}^{\circ} 27$, marzo 1928, en Notas y comentarios de La Redacción, aparece el texto "Ernesto Montenegro".

\section{RESÚMENES}

Este artículo analiza el trabajo literario realizado por Samuel Glusberg (1898-1987), conocido como Enrique Espinoza, una figura fundamental en el campo intelectual en Buenos Aires y Santiago, durante la primera mitad del siglo XX. Editor de libros y revistas, traductor y ensayista, su trabajo lo pone en el centro de la conformación de comunidades intelectuales en el periodo. El artículo propone una lectura en torno al proyecto de Babel como la puesta en práctica de un deseo comunitario, desplegado tanto en una red intelectual como en los modos y mecanismos que intentan dar sentido y cohesión a cuerpos heterogéneos de textos y autores.

Cet article analyse le travail littéraire réalisé par Samuel Glusberg (1898-1987), connu comme Enrique Espinoza, une figure fondamentale du champ intellectuel de Buenos Aires et Santiago du Chili, durant la première moitié du XXème siècle. Editeur de livres et revues, traducteur et essayiste, son travail le place au cœur de la formation des communautés intellectuelles de son temps. L'article propose une lecture autour du projet de Babel en tant que mise en œuvre d'un désir communautaire, déplié au sein d'un réseau intellectuel et au travers de modes et mécanismes qui tentent de donner un sens et une cohésion aux corpus hétérogènes de textes et auteurs.

This article analyzes the literary work carried out by Samuel Glusberg (1898-1987), known as Enrique Espinoza, a fundamental figure in the intellectual field in Buenos Aires and Santiago, during the first half of the 20th Century. Editor, director of several cultural magazines, translator and essayist, his work places him at the center of building up intellectual communities in the period. The article proposes a reading on his project, the cultural magazine Babel, as the praxis of a communitarian desire, deployed both in an intellectual network and in the forms and mechanisms that give meaning and cohesion to heterogeneous bodies of texts and authors. 
ÍNDICE

Mots-clés: Babel, communauté, hétérodoxie, réseau intellectuel

Palabras claves: Babel, comunidad, heterodoxia, red intelectual

Keywords: Babel, community, heterodoxy, intellectual network

\section{AUTORES}

JUAN JOSÉ ADRIASOLA

Universidad Alberto Hurtado

jadriaso@uahurtado.cl

LUIS VALENZUELA PRADO

Universidad Andrés Bello

luis.valenzuela.p@unab.cl 